\title{
Cognitive Behavioral Therapy (CBT) in Addressing Trauma on Children and Adolescents who Became Victims of Violence: A Literature Review
}

\author{
Habsyah Saparidah Agustina, Efri Widianti \\ Faculty of Nursing, Universitas Padjadjaran \\ Email: habsyah.rida@gmail.com
}

\begin{abstract}
Trauma is a circumstance in which a person experiences or witnesses death, feels threatened or seriously injured or a threat of physical integrity to oneself or others. Children and adolescents often had violence (harassment, neglect, embezzlement, or kidnapping) that can bring into trauma. The traumatic occurrence can have a serious psychological impact on children. To deal with this psychological hazard could be assisted by Cognitive Behavioral Therapy. This literature review aimed to identify the effect of CBT in supervising trauma in children and adolescents who became victims of violence to reduce the impact of trauma. Articles collected by Google Scholar, Science Direct and Pubmed Health used some keywords such as children, adolescent, CBT, trauma, and violence. The inclusion criteria consisted of quantitative research, systematic review, original research, full text, and published in English during 2007-2017. It identified 6 articles with 5 articles that were specifically related to CBT to supervise trauma. The results of the review of the five articles noted that 4 articles indicated that CBT is very effective in dealing with trauma in children and adolescent as the victims of violence, while 1 article showed that CBT is less effective in dealing with violence in children and adolescents. Thus, CBT was a potential intervention in addressing trauma in children and adolescent who became victims of violence, especially in West Java.
\end{abstract}

Keywords: Adolescent, children, trauma, violence. 
Habsyah Saparidah Agustina: Cognitive Behavioral Therapy (Cbt) in Addressing Trauma

\section{Introduction}

Trauma is a circumstance in which a person experiences or witnesses actual death or threatened or serious injury, or threats to the physical integrity of oneself or others. Trauma may take the form of a single or recurrent event, which is natural or human-made (such as tsunami or bombing) and intentional or unintentional (such as rape or serious illness). Exposure to traumatic occurrence may have an impact on psychological hazards such as anxiety and its symptoms, including Posttraumatic Stress Disorder (PTSD) and its symptoms; depressive disorders and its symptoms; disturbance and externalization symptoms (such as acting out, aggressive and impulsive behavior); internalize disturbance and its symptoms (such as secede, depression, or fear behavior); Idea of suicide or behavior; Drugs abuse; And a traumatic childhood filled with sadness or complicated sadness. Reactions to trauma may occur immediately after a traumatic occurrence, or weeks or months later. Many children and adolescents who have been exposed to traumatic events, showed the loss of confidence to adults and fear of recurring events. The reaction that occurs varied according to the age (Wethingto, H.R, 2008).

According to a nationally representative sample, children aged 2 to 17 years surveyed at the end of 2002 and early 2003, revealed that one of among eight children experienced a form of child abuse (including harassment, neglect, embezzlement, or kidnapping by a caretaker); one of among 12 sexuallyexperienced victims and more than one in three people witnessing violence or experience other forms of indirect sacrifice (such as murdered did by parents that unobserved by their children). (FinkelhorD, 2005) as well as data from the Indonesian Child Protection Commission (KPAI) found that there was an increase in violence against children, both sexually, physically and commercially sexual exploitation. From January to October 2013, the number of cases reached 525 cases or 15.85 percent of cases. Of this total physical violence was recorded there were 294 cases or 28 percent, psychological violence for 203 cases or 20 percent and sexual violence 535 cases or 52 percent (Mutiah, 2015).
Children and adolescents as the violence victims were social phenomena that require attention from various parties including nurses as health professionals. Almost every day, news about children with cases of physical and psychological violence can be seen in various mass media and electronic media. This systematic review study reviewed the interventions used to reduce the psychological hazard for children and adolescents, namely cognitive behavioral therapy (CBT). The therapy as the intervention reviewed a general mental and medical health response for children and adolescents who had violence, public health disasters that cause children and adolescents to have trauma. Exposure to traumatic occurrences such as physical abuse, sexual harassment, witnessing domestic violence, community violence, and natural disasters was common among US children (Stein, BD et al, 2003)

Based on the problems described above, the nurse has an important role in this case as a researcher. One role of the nurse was to identify the influence of Cognitive Behavioral Therapy (CBT) in addressing trauma in children and adolescents as the victims of violence to deal with the traumatic impact on children and adolescents. All the articles collected were analyzed with the main question, How was the impact of cognitive behavioral therapy (CBT) in addressing trauma in children and adolescents as the victims of violence?

\section{Research Method}

The method used in determining the literature was by using literature searching on database/ search engines like Google Scholar, Science Direct, and Pubmed Health. Then enter the keyword. Articles that appear will be selected based on the inclusion criteria and articles excluded because there were exclusive criteria or inappropriate to the inclusion criteria.

The inclusion criteria, were the research conducted in the range of 2007-2017, published in reputable journals, focusing on cognitive behavioral therapy (CBT) interventions, for traumatized children, 
Habsyah Saparidah Agustina: Cognitive Behavioral Therapy (Cbt) in Addressing Trauma

trauma, original research, and systematic review. Exclusion criteria were a research included in Beal's List of Predator Journals, a pilot study or feasibility study, and journals which inaccessible in full text. The database used was Google Scholar for 2 articles, Pubmed Health for 5 articles, and Science Direct for 9 articles, so the total obtained 16 articles. Screened through exclusion and inclusion criteria, then reached 5 full-text articles. Keywords used were children AND adolescent AND CBT AND trauma AND violence.

\section{Research Results}

There was a small difference in the obtained results from these 5 articles. According to Ozabaci, Nilufer (2011), six of the studies included in the review (307 participants) stated that cognitive behavioral therapy (CBT) had a small impact on reducing violence in children and adolescents compared to the control group (mean-effect size -0.094). Whilst, according to the Silverman's study, WK, Ortiz, CD, Viswesva, C. (2008), of 23 research studies revealed that the mean effects for treatment versus control were 0.43 (PTSS), 0.24 (depression), 0, 09 (anxiety) and 0.22 (externalizing behavior problems), which suggested moderate clinical effects for these results. Significant treatment effects were found in PTSS for cognitive behavioral therapy (CBT) interventions (ES 0.50, 95\% CI $0.03-0.98 ; n=1.320)$ and sexual harassment interventions (ES 0.46, 95\% CI $0,14-0.79 ; \mathrm{n}=1.052)$. No significant results for other results were reported. It means, the use of CBT intervention was superior to nonCBT intervention (ES 0.24 versus 0.02); To overcome the problem of behavior, however, in the treatment of sexual harassment was less effective when compared to other types of trauma treatment (ES 0.19 versus 0.28 )

The research of Wethington, H.R., Hanh, R.A., Fuqua-Withley, D.S et al. (2008) also reinforces the assertion that CBT therapy was effective in reducing the psychological impact on traumatized children and adolescents. This study was conducted by meta-analysis. Subjects in the study were mean age under 21 years, exposed to individuals/mass, intentional/unintentional, or community guide) showed that individual and group cognitive behavioral therapy could reduce psychological disadvantages among symptomatic children and adolescents exposed to trauma. Inadequate evidence was to determine the effectiveness of playing therapy, art therapy, pharmacological therapy, psychodynamic therapy in reducing psychological hazards.

It was reinforced by the research of Cary, C.E \& MCMillen, J.C. (2012) which stated that ten studies (twelve articles) were selected for inclusion in three sets of meta-analyzes found that significant differences between FCBT conditions and comparative conditions in their ability to reduce PTSD symptoms ( $G$ $=.671)$, depression $(\mathrm{g}=.378)$ and behavioral problems $(\mathrm{g}=.247)$ immediately after completion of treatment. This difference applied to PTSD at twelve months after completion of treatment (0.389) but does not persist for depression or behavioral problems. There was no significant difference between TF-CBT conditions and alternatives. Active control conditions were completed soon after the treatment. Therefore, TF-CBT was an effective intervention for the treatment of PTSD in youth. It means this systematic study was able to identify that TF-CBT was effective for the treatment of PTSD on children. It may speed up the recovery of depression and post-traumatic behavior.

\section{Discussion}

The research of Rolfsnes, E.S \& Idsoe, T. (2011) conducted by systematic review and meta-analysis. In this article, there were nineteen studies (4,655 participants) included in the review; eight randomized controlled trials (RCTs), 10 quasi-experimental studies and one randomized study group. The sample size ranged from 26 to 2,500 students. Sixteen studies used the method of cognitivebehavioral therapy as the main treatment approach, and three remaining studies each used game/art, eye engines desensitization and reprocessing and mind-body skills. The results showed that there was a large media effect on school-based intervention programs to reduce PTSD symptoms on students with 
Habsyah Saparidah Agustina: Cognitive Behavioral Therapy (Cbt) in Addressing Trauma

an average effect size $\mathrm{d}=0.68(\mathrm{SD}=0.41)$. This study also found some advantages that the interventions delivered in schools can be effective in helping children and adolescents who had various traumatic occurrences.

\section{Conclusion}

Within this systematic review, there were 5 study articles related to cognitive behavioral therapy (CBT) interventions in addressing trauma on children and adolescents who became the victims of violence to deal with the traumatic impact on children and adolescents. This TF-CBT intervention was administered to children and adolescents who had varying degrees of trauma. Among 5 articles reviewed, there was an article showed the small effectiveness of CBT in dealing with violence on children and adolescents but the other four articles stated that it was very effective.

\section{References}

Cary, C.E \& MCMillen, J.C. (2012). The data behind the dissemination: Asystematic review of trauma-focused cognitive behavioral therapy for use with children and youth. Children and Youth Services Review, 34, 748757. doi:10.1016/j.childyouth.2012.01.003.

Finkelhor D, Ormrod R, Turner H, Hamby SL. (2005). The victimization ofchildren and youth: a comprehensive, national survey. Child Maltreat;10:5-25.
Mutiah, D. (2015). Faktor-faktor yang mempengaruh kekerasan terhadap anak. Fakultas Psikologi UIN Jakarta. Tersedia dalam repository.uinjkt.ac.id. Diakses pada 20 April 2017 Pkl. 19.41.

Rolfsnes, E.S \& Idsoe, T. (2011). Schoolbased intervention programs for ptsd symptoms: a review and meta-analysis. Journal of Traumatic Stress, 24,(2), pp. 155165 DOI: $10.1002 /$ jts. 20622.

Silverman, W.K., Ortiz, C.D., Viswesva, C. (2008). Evidence-Based PsychosocialTreatments for Children and Adolescents Exposed to Traumatic Events. Journal of Clinical Child \& Adolescent Psychology, 37(1), 156-183. ISSN: 15374416 print $=1537-4424$ online. DOI: $10.1080 / 15374410701818293$.

Stein BD, Jaycox LH, Kataoka S, Rhodes HJ, Vestal K. (2003) Prevalence of child and adolescent exposure to community violence. Clin Child Fam Psychol Rev;6:247- 64.

Ozabaci, Nilufer.(2011). Cognitive behavioural therapy for violent behaviour in children and adolescents: A meta-analysis. Children and Youth Services Review 33. 19891993. doi:10.1016/j.childyouth.2011.05.027.

Wethington, H.R., Hanh, R.A., FuquaWithley, D.S et al. (2008). The Effectiveness of Interventions to Reduce Psychological Harm from Traumatic Events Among Children and Adolescents: A Systematic Review. American Journal of Preventive Medicine, 35(3):287313) doi:10.1016/j.amepre.2008.06. 